\title{
THE VALUE OF POSTURAL REDUCTION IN THE INITIAL MANAGEMENT OF CLOSED INJURIES OF THE SPINE WITH PARAPLEGIA AND TETRAPLEGIA
}

\author{
PART I \\ H. L. Frankel, D. O. Hancock, G. Hyslop, J. Melzak, L. S. Michaelis, \\ G. H. Ungar, J. D. S. Vernon and J. J. Walsh \\ National Spinal Injuries Centre, Stoke Mandeville Hospital, Aylesbury
}

SINCE the founding of the National Spinal Injuries Centre at Stoke Mandeville Hospital the method of postural reduction has been used in the management of closed spinal injuries. During the 25 years the method has gained increasing acceptance in spinal injury centres throughout the world although some authors give virtually no treatment to the bony lesion and others advocate a variety of early operations ranging from decompression laminectomies to fusion or plating with various techniques (Covalt et al., I953; Holdsworth and Hardy, 1953; Cloward, 196I; Harris, I963; Holdsworth, I963).

The methods of postural reduction used at Stoke Mandeville Hospital have been frequently described (Guttmann, 1953, 1963). The authors of this paper are the present senior medical staff of the National Spinal Injuries Centre together with two who have recently retired. All of us are pupils and former co-workers of Sir Ludwig Guttmann and we consider it appropriate to analyse the results of this method of treatment for publication in the issue of Paraplegia commemorating Sir Ludwig's seventieth birthday. The purpose of this study is to describe the bony lesions, their management and the results of postural reduction on the bony and spinal cord lesions.

Material and Methods. All patients with closed spinal injuries who were admitted within I4 days of injury and where adequate notes and X-rays were available are included in the survey. The patients were admitted to Stoke Mandeville Hospital between March I95I and August 1968 and included 682 patients, 593 males and 69 females. The patients were divided into four groups on the basis of their initial skeletal injury:

I. Cervical fractures and fracture-dislocations.

2. Dorsal fractures and fracture-dislocations (excluding 3 below).

3. Dorso-lumbar fractures and fracture-dislocations (fractures and fracturedislocations involving $\mathrm{TII}_{\mathrm{I}}$ or $\mathrm{T}_{\mathrm{I}} 2$ or $\mathrm{LI}$ vertebrae).

4. Lumbar fractures and fracture-dislocations (excluding 3 above).

Where there was no visible fracture or dislocation on any X-rays, the results will be given separately in the section most appropriate to the neurological lesion.

The distribution of the patients and the causes of the injuries are shown in Table I. All patients who had had operations on the spine before admission to Stoke Mandeville and the one patient who had an open reduction at Stoke Mandeville Hospital are excluded from further analysis in this paper, as are all patients who died in the first three months or who were discharged from Stoke Mandeville 
TABLE I

Causes of Skeletal Injury related to Skeletal Levels

\begin{tabular}{|c|c|c|c|c|c|c|}
\hline \multirow{3}{*}{ Road Accidents } & & \multirow[t]{2}{*}{ Cervical } & \multirow[t]{2}{*}{ TI-IO } & \multirow[t]{2}{*}{$\mathrm{TII}_{\mathrm{I}}$ I2; LI } & \multirow[t]{2}{*}{ Lumbar $\mathrm{i}$} & Total \\
\hline & & & & & & \\
\hline & river. & 46 & 20 & 24 & 3 & 93 \\
\hline pas & nger & 42 & 23 & $2 \mathrm{I}$ & 3 & 89 \\
\hline Motor cycle: $\mathrm{dr}$ & & 36 & 50 & 12 & I & 99 \\
\hline & & I & 6 & 5 & 2 & I4 \\
\hline Bicycle & & I 2 & 5 & 7 & 0 & 24 \\
\hline Pedestrian & & II & 2 & 8 & o & $\frac{21}{-} 340$ \\
\hline Aeroplane & . & I & I & 6 & o & 8 \\
\hline \multicolumn{7}{|l|}{ Work } \\
\hline Fall down & . & I6 & $3 \mathrm{I}$ & 62 & 4 & II3 \\
\hline Dropped upon & . & 2 & 8 & I2 & 3 & 25 \\
\hline Crushed & . & 2 & 3 & I9 & 2 & 26 \\
\hline Hit . & . & 4 & 0 & 12 & 0 & I6 \\
\hline Other & . & I & o & 0 & 0 & $\stackrel{I}{I}_{\mathrm{I}} \mathrm{I}$ \\
\hline \multicolumn{7}{|l|}{ Domestic } \\
\hline Fall down & . & 28 & I8 & 15 & I & 62 \\
\hline Dropped upon & . & 0 & I & 0 & 0 & I \\
\hline Crushed & . & 0 & I & I & 0 & 2 \\
\hline Hit. & . & I & I & I & 0 & 3 \\
\hline Other & . & I & 2 & I & o & 4 \\
\hline \multicolumn{7}{|l|}{ Sport } \\
\hline Diving & & $4 \mathrm{I}$ & 0 & I & 0 & 42 \\
\hline Riding : & . & 0 & 4 & 3 & I & 8 \\
\hline Rugby football & & 5 & 0 & 0 & 0 & 5 \\
\hline Gymnastics & . & 5 & 0 & 0 & 0 & 5 \\
\hline Other & & 4 & I & 4 & 2 & II \\
\hline Assault & & 0 & I & I & o & 2 \\
\hline Attempted suicide & & 0 & 4 & 3 & I & 8 \\
\hline & Total & 259 & 182 & 218 & 23 & 682 \\
\hline
\end{tabular}

Hospital prematurely for any reason. This leaves a total of 612 patients whose results will be analysed in detail, i.e. 218 with cervical injuries, I66 with dorsal injuries, 205 with dorso-lumbar and 23 with lumbar injuries.

Method of Extraction of Information. A special sheet was filled in for each patient, all the authors participating in this work. A completed sheet is shown on Table II. 
TABLE II

\section{Analysis Proforma Sheet}

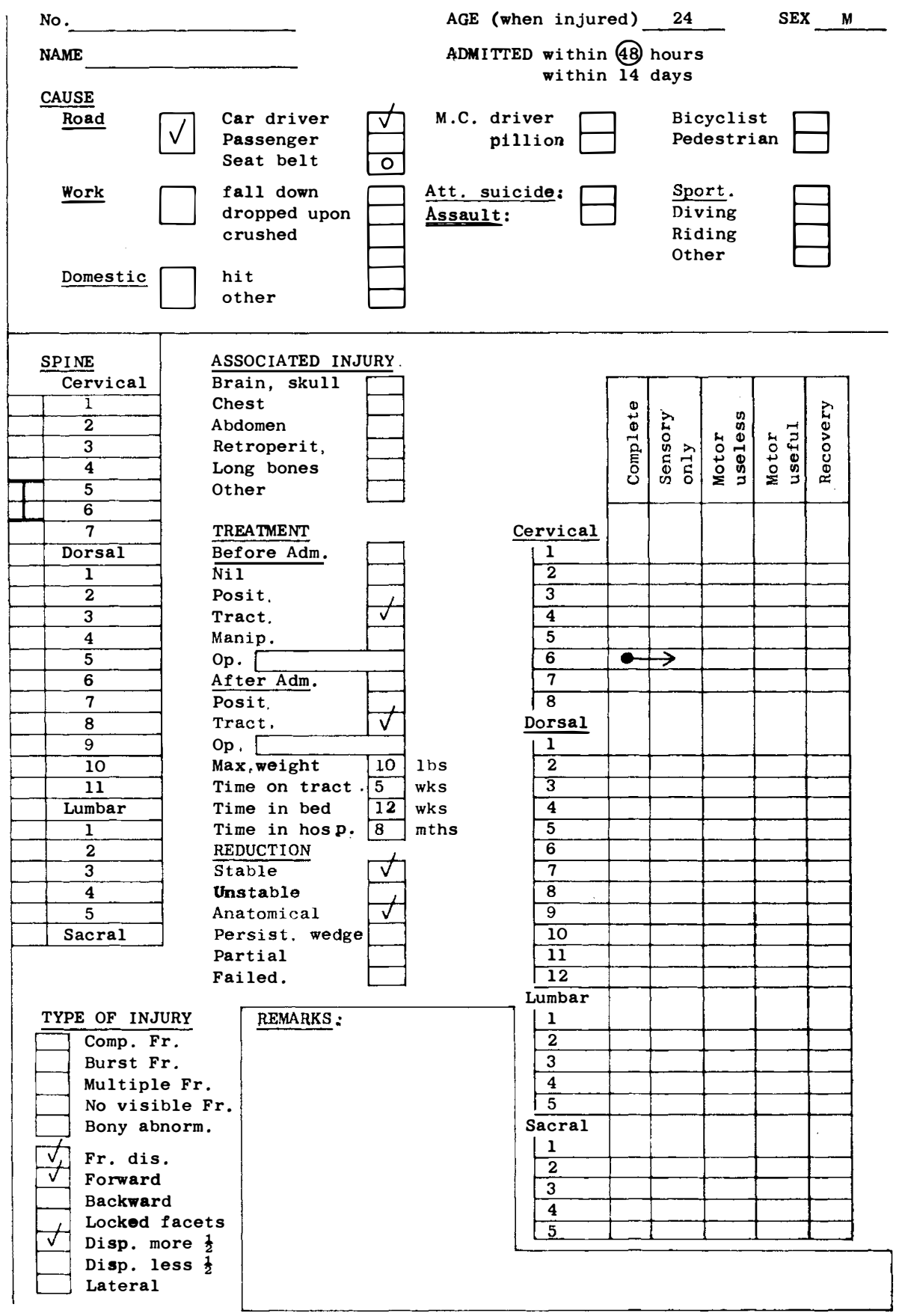


The top section gives personal details and the causes of the spinal injury. In the left column headed 'spine' the level of the fracture or fracture-dislocation, if any, is marked. In the case of a simple fracture only the relevant vertebra is marked but in the case of fracture-dislocation all the vertebrae involved are marked. Below this (under type of injury), further marks are made; if there was a fracture-dislocation, then its direction was indicated, always describing it as a dislocation of the upper upon the lower vertebra. The centre column starts with the main associated injuries. Below this there is a description of the treatment of the skeletal lesion which was given in the referring hospital, and below this at Stoke Mandeville Hospital. Further down, the end-result of reduction or attempted reduction is given. The words 'stable' and 'unstable' refer to the final result and not to the initial lesion. By 'anatomical' we mean that the X-ray shows the vertebral bodies to be of normal contour and in a normal position and there may also be evidence of bony bridging between the previously deformed or dislocated vertebrae.

The neurological progress is indicated in the right-hand column, the lesion on admission to Stoke Mandeville Hospital being marked by a dot and the lesion on discharge by an arrow head. Because of the large number of patients involved it was found necessary to confine the classification to five different grades which are defined as follows:

I. 'Complete' (A). This means that the lesion was found to be complete both motor and sensory below the segmental level marked. If there was an alteration of level but the lesion remained complete below the new level, then the arrow would point up or down the 'complete' column.

2. 'Sensory only' (B). This implies that there was some sensation present below the level of the lesion but that the motor paralysis was complete below that level. This column does not apply when there is a slight discrepancy between the motor and sensory level but does apply to sacral sparing.

3. 'Motor Useless' (C). This implies that there was some motor power present below the lesion but it was of no practical use to the patient.

4. 'Motor Useful' (D). This implies that there was useful motor power below the level of the lesion. Patients in this group could move the lower limbs and many could walk, with or without aids.

5. 'Recovery' (E). This implies that the patient was free of neurological symptoms, i.e. no weakness, no sensory loss, no sphincter disturbance. Abnormal reflexes may have been present.

The method of filling in the sheet is shown in Table II, which summarises the case of a male aged 24, injured in a road accident as the driver of a car not wearing a safety belt. Admitted to Stoke Mandeville Hospital within 48 hours, he sustained a fracture-dislocation of $\mathrm{C}_{5}$ on $\mathrm{C}_{6}$ vertebrae, the dislocation consisting of $\mathrm{C}_{5}$ forward on C6 by less than half of a vertebral body. He had no associated injuries and was treated by skull traction in the referring hospital. Traction was continued at Stoke Mandeville Hospital for a total time of five weeks, the maximum weight used being Io $\mathrm{lb}$. He remained in bed for 12 weeks and was discharged from hospital after eight months, the final reduction being stable in an anatomical position. On admission he had a complete tetraplegia below C6 segment and on discharge there was some sensory recovery only.

We appreciate that our classification of the bony lesion and its degree of reduc- 
tion as well as the neurological classifications is relatively crude. However, for the purpose of this paper we needed a system whereby most cases fell clearly into a specific category and which gave results which could be analysed.

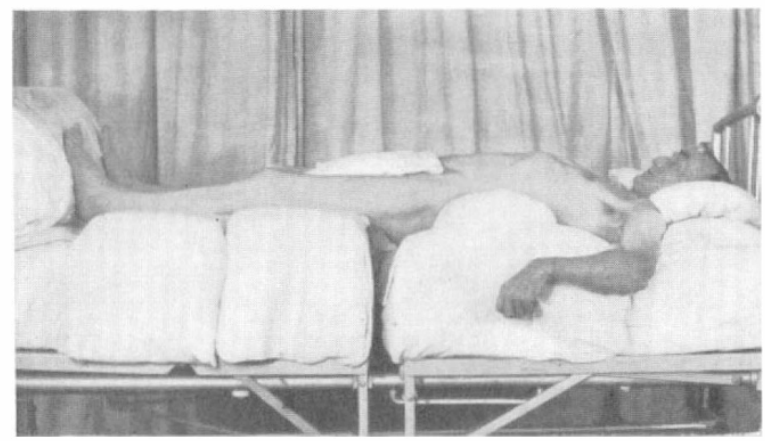

FIG. I

Old method of nursing on packs and turning by orderlies. The patient on his back. Note pillow maintaining extension of dorso-lumbar spine.

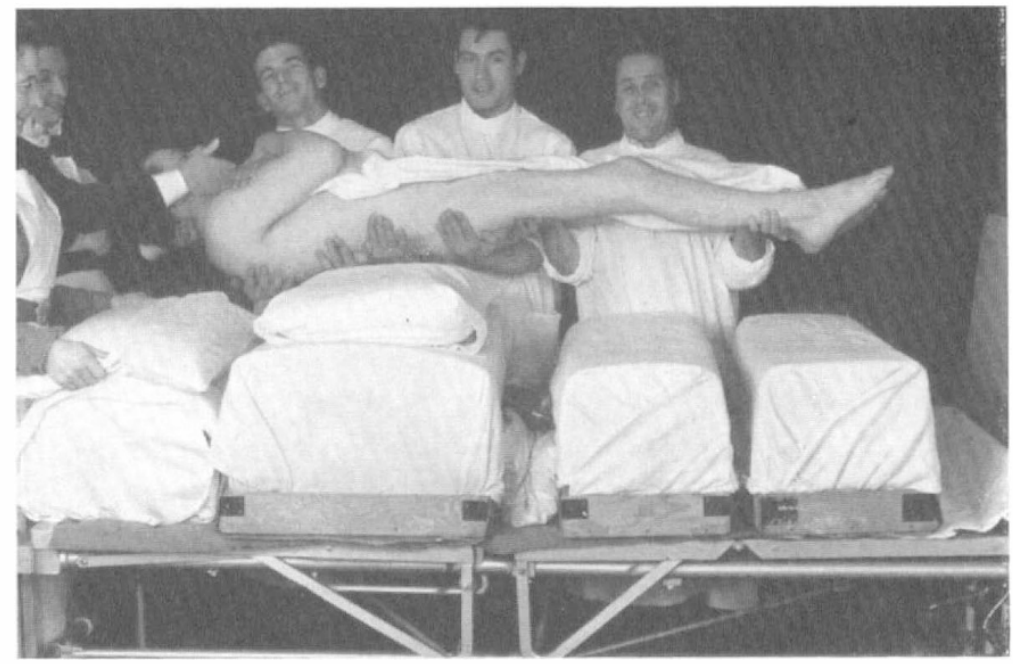

FIG. 2

Lifted out of bed between turns. Note right hand of middle orderly maintaining extension.

Method of Treatment. Before 1964-65 all patients were nursed initially on sorbo packs and turned every three hours by a team of orderlies under the supervision of a nurse or Sister (figs. I to 3). Since 1964-65 all patients have been nursed on the Stoke Mandeville Egerton turning-beds and turned on these beds at least every three hours (figs. 4 and 5). With both these methods, pillows or rolls 
were used in addition at the appropriate sites to try to reduce the fracture or fracturedislocation. These pillows and rolls were most frequently used to produce varying degrees of extension but, where indicated, could also place the spine in a neutral or flexed position. Progress was controlled by frequent check X-rays, the position being changed if necessary. In the case of cervical lesions (particularly those with

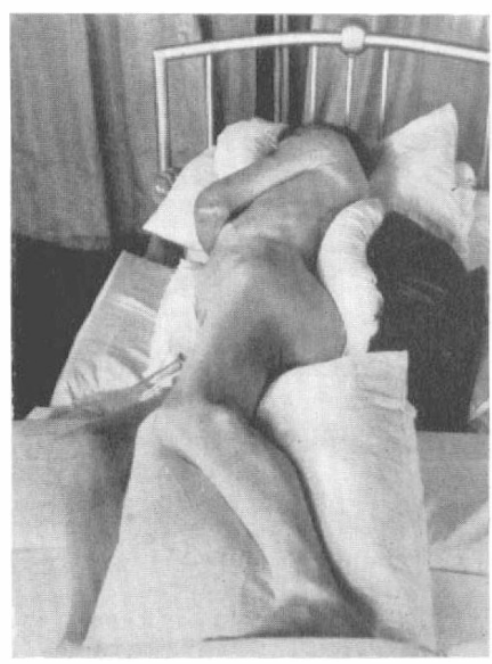

FIG. 3
Fig. 3-The patient on his side. Note pillow supported by sandbag maintaining extension.

Fig. 4-Postural reduction of a flexion-injury with fracture-dislocation of the cervical spine, using skull traction and the Egerton-Stoke Mandeville Turning Bed. The patient is on his back. Note soft roll maintaining normal lordosis of neck. Cone's tongues.

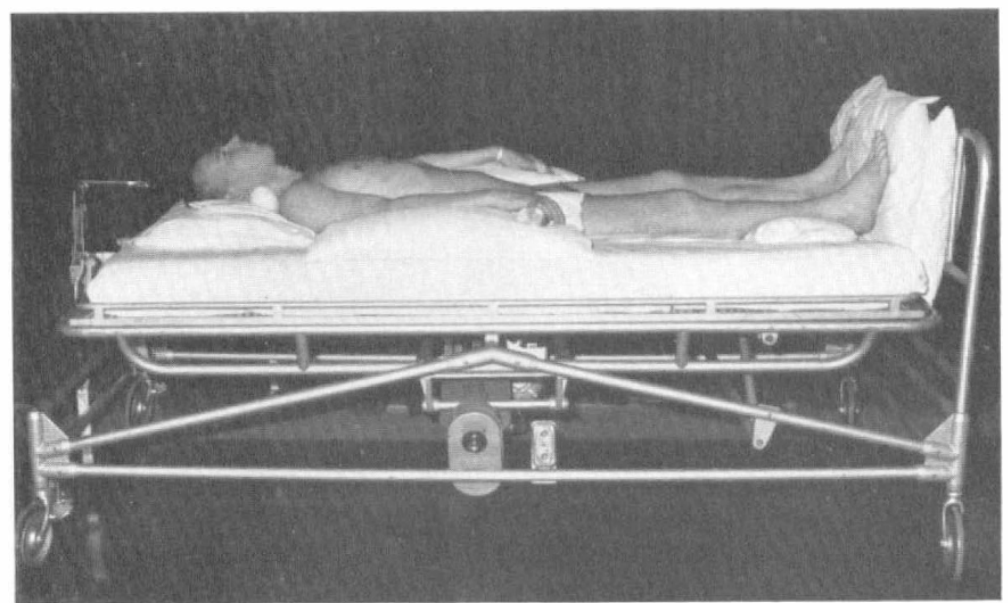

FIG. 4

locked facets), several different positions and weights were tried at times. During these attempts frequent, sometimes hourly, neurological examinations were necessary and if there was any evidence of neurological deterioration the methods were adjusted. When the optimal position was achieved, this was maintained until there was either X-ray evidence of bony union or a 'safe' time had elapsed. The latter 
depended on the judgment of the clinician and was influenced by whether there was any sign of neurological recovery. When the patients first sat up the cervical patients usually wore some form of collar, and the patients with low dorsal or lumbar lesions wore a light plastic 'jacket' for several weeks.

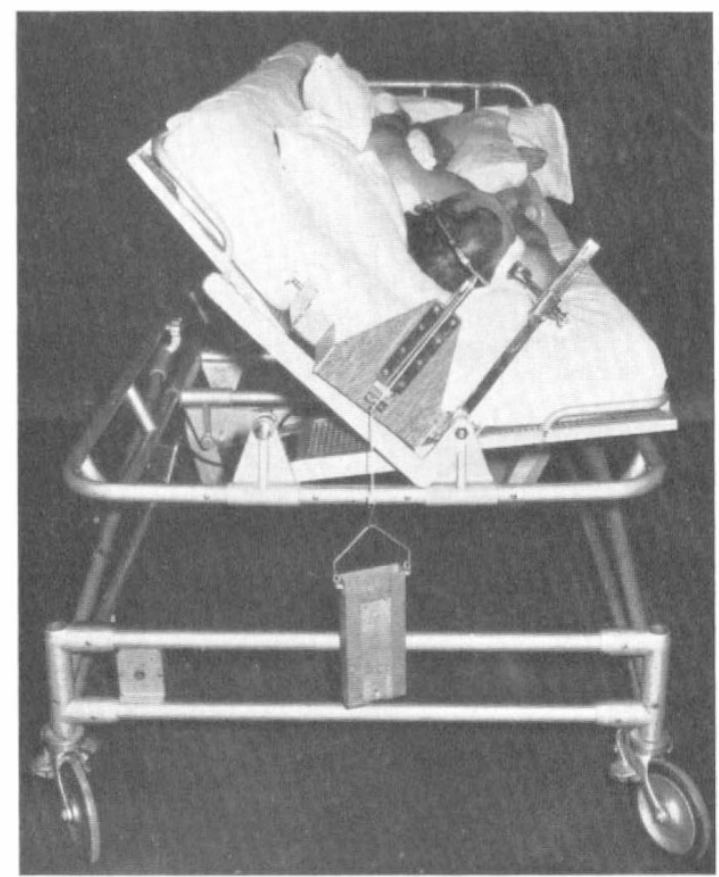

FIG. 5

Patient turned on to right side. Note $50^{\circ}$ tilt, the slight raising of the right third of the bed and the automatically maintained alignment of head traction which is fixed to the middle third of the mattress.

\section{RESULTS}

I. Cervical Injuries. The results are shown in Tables IIIA and IIIв. The first column shows the numbers with each type of bony lesion, the second column shows the degree of reduction achieved, the next column shows the distribution of the various degrees of neurological damage on admission and the right-hand column the neurological lesion on discharge. This table was designed to show correlation between the type of bony lesion, its degree of reduction and the neurological progress. Table IIIA cannot show precisely how many patients deteriorated or improved but this information is shown in Table IIIB which provides this information for the cervical group as a whole. In each square of the grid are two letters of the alphabet, the first relating to the neurological lesion on admission and the second to the neurological lesion on discharge. Therefore the numbers within the heavy lines represent patients with neurological lesions unchanged, those in squares 


\section{TABLE IIIA}

Cervical Injuries

\begin{tabular}{|c|c|c|c|c|c|c|c|c|c|c|c|c|c|}
\hline \multicolumn{5}{|c|}{ SKELETAL INJURY } & \multicolumn{9}{|c|}{ CORD INJURY } \\
\hline \multirow{2}{*}{\multicolumn{2}{|c|}{ Type }} & \multirow{2}{*}{\multicolumn{2}{|c|}{ Degree of reduction }} & \multirow[b]{2}{*}{ A } & \multicolumn{4}{|c|}{ On admission } & \multicolumn{5}{|c|}{ On discharge } \\
\hline & & & & & $\mathrm{B}$ & $\mathrm{C}$ & $\mathrm{D}$ & $\mathrm{E}$ & A & B & $\mathrm{C}$ & $\mathrm{D}$ & $\mathrm{E}$ \\
\hline $\begin{array}{l}\text { Compression } \\
\text { Fractures }\end{array}$ & 36 & $\begin{array}{l}\text { Anatomical } \\
\text { Residual wedge } \\
\text { Partial } \\
\text { Failed }\end{array}$ & $\begin{array}{r}13 \\
20 \\
3\end{array}$ & $\begin{array}{r}5 \\
9 \\
I \\
-\end{array}$ & $\begin{array}{l}\text { I } \\
5 \\
- \\
--\end{array}$ & $\begin{array}{r}\text { I } \\
4 \\
-\end{array}$ & $\begin{array}{r}6 \\
2 \\
2 \\
\end{array}$ & \begin{tabular}{l|l}
- & $\vdots$ \\
$-\ldots$ & \\
- &
\end{tabular} & $\begin{array}{l}- \\
4 \\
I\end{array}$ & $\begin{array}{l}2 \\
4 \\
-\ldots\end{array}$ & $\begin{array}{r}\text { I } \\
2 \\
-- \\
-\end{array}$ & $\begin{array}{l}7 \\
9 \\
2\end{array}$ & $\begin{array}{r}3 \\
\mathrm{I} \\
- \\
\end{array}$ \\
\hline $\begin{array}{l}\text { Burst } \\
\text { Fractures }\end{array}$ & 12 & $\begin{array}{l}\text { Anatom } \\
\text { Residua } \\
\text { Partial } \\
\text { Failed }\end{array}$ & $\begin{array}{l:l}9 & \\
2 & \\
\mathrm{I} & \\
- & \end{array}$ & $\begin{array}{r}2 \\
2 \\
-\end{array}$ & $\begin{array}{r}5 \\
-\cdots \\
I \\
-\end{array}$ & - & $\frac{2}{-}$ & $\frac{\cdots}{-}$ & $\begin{array}{r}\mathbf{I} \\
\mathbf{2} \\
\cdots\end{array}$ & $\begin{array}{r}5 \\
I \\
-\end{array}$ & $\frac{-\cdots}{-}$ & $\frac{2}{-}$ & $\begin{array}{l}\mathrm{I} \\
-- \\
--\end{array}$ \\
\hline $\begin{array}{l}\text { Fracture- } \\
\text { Dislocations } \\
\text { Displaced }<\frac{1}{2}\end{array}$ & 129 & $\begin{array}{l}\text { Anatom } \\
\text { Residua } \\
\text { Partial } \\
\text { Failed }\end{array}$ & $\begin{array}{r}37 \\
34 \\
50 \\
8\end{array}$ & $\begin{array}{r}16 \\
25 \\
32 \\
6\end{array}$ & $\begin{array}{l}5 \\
4 \\
8 \\
1\end{array}$ & $\begin{array}{r}4 \\
4 \\
5 \\
\end{array}$ & $\begin{array}{r}\mathrm{I} 2 \\
\mathrm{I} \\
5 \\
\mathrm{I}\end{array}$ & $\begin{array}{c}\cdots \cdots \cdot \\
\cdots \cdots- \\
-\cdots\end{array}$ & $\begin{array}{r}9 \\
17 \\
28 \\
4\end{array}$ & $\begin{array}{l}3 \\
6 \\
4 \\
1\end{array}$ & $\begin{array}{l}4 \\
\mathrm{I} \\
6 \\
\mathrm{I}\end{array}$ & $\begin{array}{r}\text { I } 4 \\
8 \\
9 \\
\end{array}$ & $\begin{array}{l}7 \\
2 \\
3 \\
2\end{array}$ \\
\hline $\begin{array}{l}\text { Fracture- } \\
\text { Dislocations } \\
\text { Displaced }>\frac{1}{2}\end{array}$ & 25 & $\begin{array}{l}\text { Anatomical } \\
\text { Residual wedge } \\
\text { Partial } \\
\text { Failed }\end{array}$ & \begin{tabular}{r|r}
7 \\
4 \\
$\mathrm{I}$ \\
3
\end{tabular} & $\begin{array}{r}5 \\
3 \\
10 \\
2\end{array}$ & $\begin{array}{c}2 \\
- \\
-\cdots \\
-\end{array}$ & $\begin{array}{r}\text { I } \\
- \\
-\end{array}$ & I & $\begin{array}{l}\cdot \\
- \\
- \\
-!\end{array}$ & $\begin{array}{l}2 \\
3 \\
8 \\
2\end{array}$ & $\frac{3}{I}$ & $\begin{array}{l}\text { I } \\
-\cdots- \\
-\end{array}$ & $\begin{array}{r}\text { I } \\
\text { I } \\
\mathbf{2} \\
-\cdots\end{array}$ & - \\
\hline No bony injury & I6 & & & 5 & I & 2 & 8 & - & 3 & I & - & II & I \\
\hline Total & 218 & & & 123 & 33 & $2 \mathrm{I}$ & $4 \mathrm{I}$ & - & 84 & $3 I$ & I6 & 66 & $2 \mathrm{I}$ \\
\hline
\end{tabular}

TABLE IIIb

Cervical Injuries

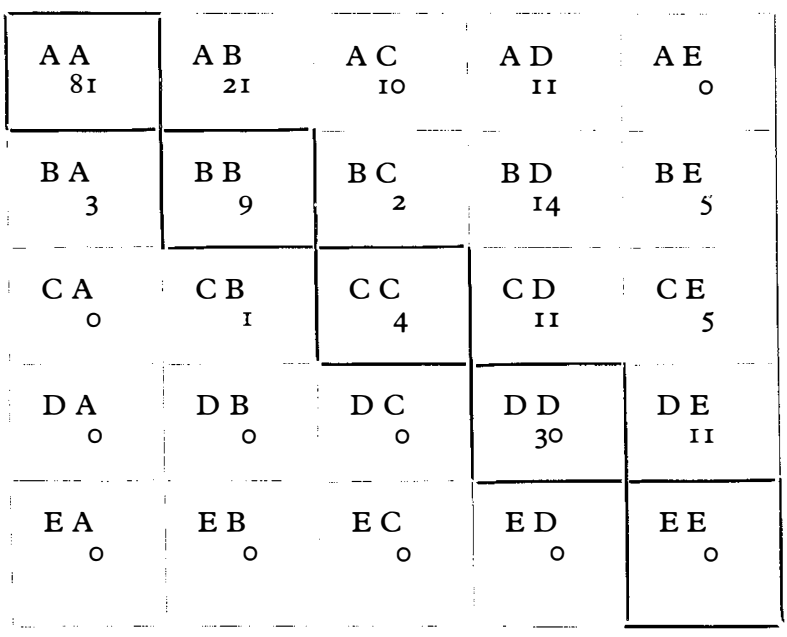

In each square of the grid are two letters of the alphabet, the first related to the neurological lesion on admission and the second to the neurological lesion on discharge. 
POSTURAL REDUCTION IN CLOSED INJURIES OF THE SPINE

TABle IVA

TI-Tıo Injuries

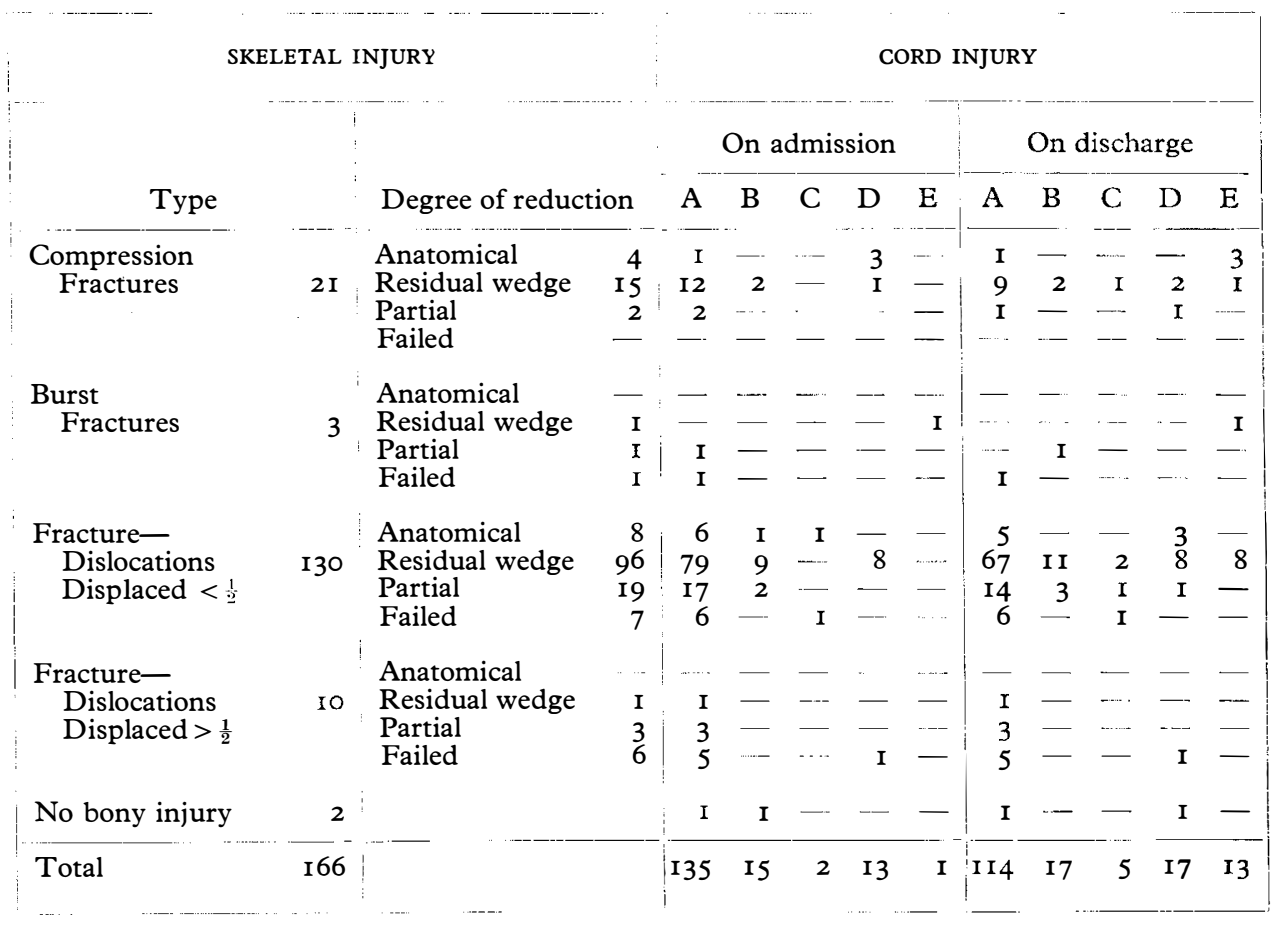

Table IVb

TI-Tıo Injuries

\begin{tabular}{|c|c|c|c|c|}
\hline$\underset{\text { I I } 4}{A ~ B ~}$ & A $\underset{\text { I I }}{B}$ & $\mathrm{~A} \mathrm{C}_{2}$ & $\begin{array}{r}\text { A D } \\
7\end{array}$ & A $\underset{I}{E}$ \\
\hline B A & $\begin{array}{l}\text { B B } \\
6\end{array}$ & $\mathrm{~B} \mathrm{C}_{2}$ & $\begin{array}{r}B \text { D } \\
5\end{array}$ & $\begin{array}{r}\mathrm{B} E \\
2\end{array}$ \\
\hline $\begin{array}{r}\mathrm{CA} \\
\mathrm{O}\end{array}$ & $\begin{array}{c}\mathrm{C} B \\
0\end{array}$ & $\mathrm{C} \mathrm{C}_{\mathrm{I}}$ & $\underset{I}{C ~ D ~}$ & $\begin{array}{r}\mathrm{C} E \\
\mathrm{O}\end{array}$ \\
\hline $\begin{array}{r}\mathrm{DA} \\
\mathrm{O}\end{array}$ & D B & $\begin{array}{r}\mathrm{DC} \\
\mathrm{O}\end{array}$ & $\begin{array}{r}\mathrm{D} D \\
4\end{array}$ & $\begin{array}{r}\mathrm{DE} \\
9\end{array}$ \\
\hline $\begin{array}{l}\text { E A } \\
\text { o }\end{array}$ & $\begin{array}{c}\text { E B } \\
\text { o }\end{array}$ & $\begin{array}{r}\mathrm{EC} \\
\mathrm{O}\end{array}$ & $\begin{array}{r}\text { E D } \\
\text { o }\end{array}$ & $\mathrm{EE}_{\mathrm{I}}$ \\
\hline
\end{tabular}

In each square of the grid are two letters of the alphabet, the first related to the neurological lesion on admission and the second to the neurological lesion on discharge. 
TII, TI2, LI Injuries

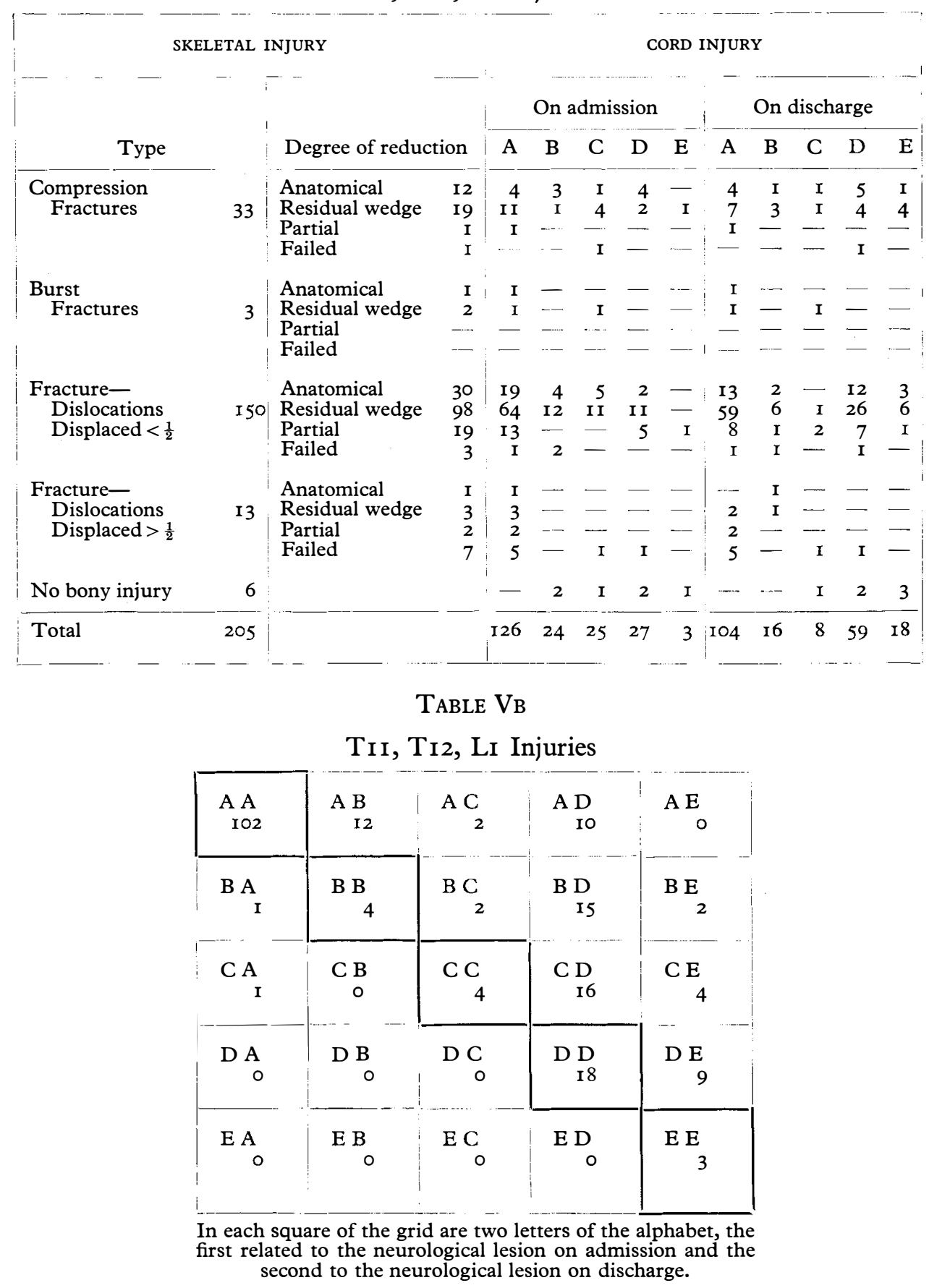


TABLE VIa

\section{Lumbar Injuries}

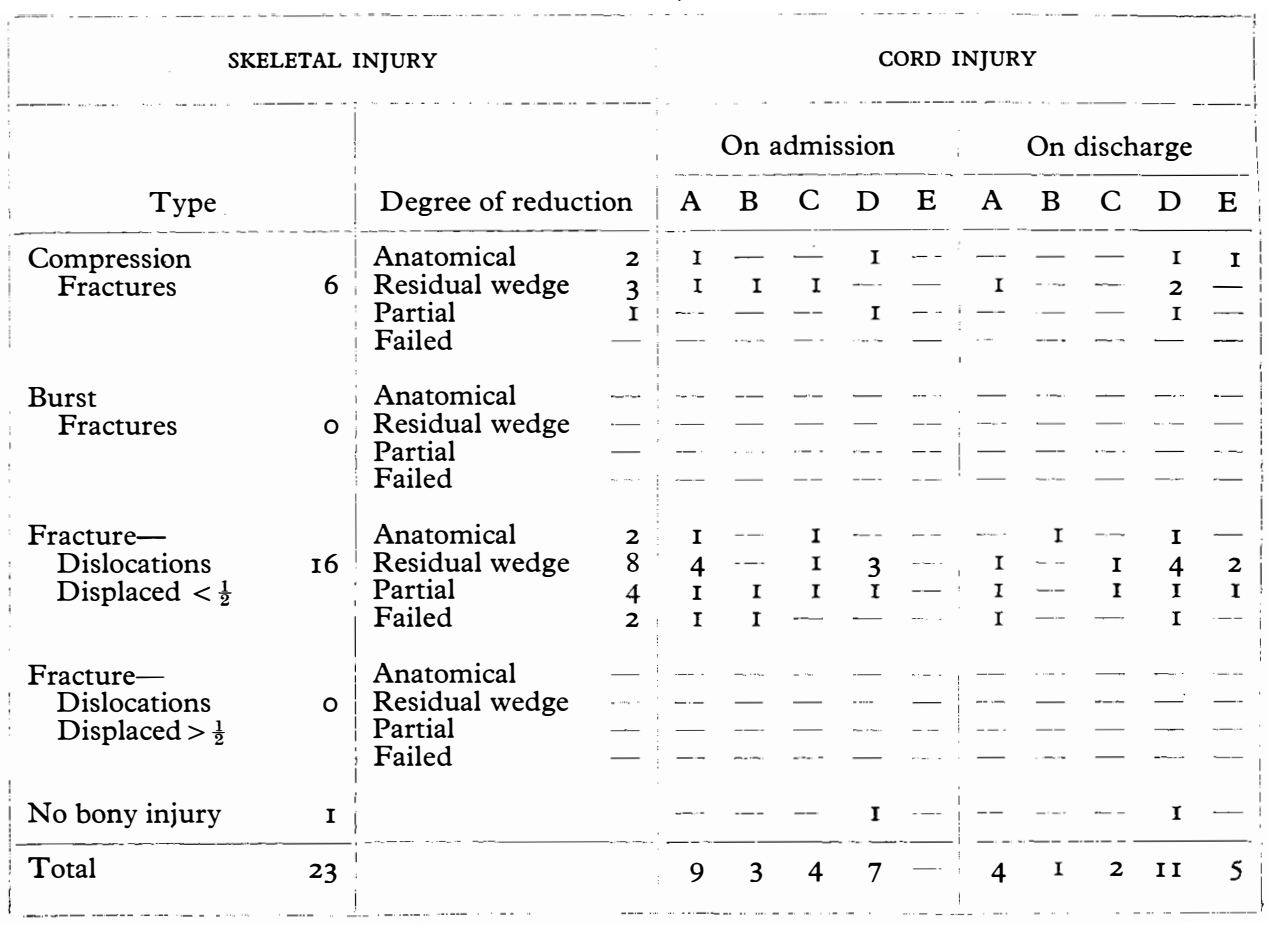

TABLE VIB

Lumbar Injuries

\begin{tabular}{|c|c|c|c|c|}
\hline A A & A B & A C & A D & A E \\
\hline 4 & I & O & 4 & 0 \\
\hline B A & B B & B C & B D & B E \\
\hline I & 0 & 2 & 0 \\
\hline C A & C B & C C & C D & C E \\
\hline 0 & 0 & I & 0 \\
\hline D A & D B & D C & DD & D E \\
\hline 0 & 0 & 0 & 2 & 5 \\
\hline E A & E B & E C & E D & E E \\
\hline 0 & 0 & 0 & 0 & 0 \\
\hline
\end{tabular}

In each square of the grid are two letters of the alphabet, the first related to the neurological lesion on admission and the second to the neurological lesion on discharge. 
above the heavy lines improved and those in squares below the lines deteriorated. Improvement or deterioration is shown only if it was sufficient to change the patient from one neurological group $(\mathrm{A}, \mathrm{B}, \mathrm{C}, \mathrm{D}, \mathrm{E})$ to another.

In the cervical group out of 123 patients with initially complete lesions 42 became incomplete to some degree while 3 patients with initially incomplete lesions became complete. There is no clear correlation between the bony lesions and the various degrees of reduction and the neurological lesions.

2. Dorsal Injuries. Tables IVA and IVB show the results in the same way as in the previous tables. Compared with the cervical injuries there is a greater number of initially complete lesions and a smaller number with subsequent improvement.

3. Dorso-lumbar Injuries. The results are shown in Tables VA and VB. The neurological lesions on admission show a similar pattern to the cervical group but on discharge a rather higher number continue to have complete lesions.

4. Lumbar Injuries. The results are shown in Tables VIA and VIB. The numbers are small but this group seems to show the best neurological function both on admission and on discharge.

Time in Bed. The average time that the patients were kept in bed before sitting up is noted below, but patients who were kept in bed for reasons other than the vertebral injury, e.g. associated fractures, were excluded.

Cervical fractures, I0 8 weeks.

Cervical fracture-dislocations, $12 \cdot 0$ weeks.

Cervical: no visible fracture, I0.0 weeks.

Ti-Io fractures, $9 \cdot 8$ weeks.

TI-IO fracture-dislocations, II $\cdot$ I weeks.

TI-IO no visible fracture, I I $\cdot 0$ weeks.

TiI, Ti2-Li fractures, II 3 weeks.

TiI, TI2-Li fracture-dislocations, I2.0 weeks.

TII, TI2-Li no visible fracture, $6 \cdot 6$ weeks.

Lumbar fractures, I3 weeks.

Lumbar fracture-dislocations, $12 \cdot 2$ weeks.

Stability. Four patients developed an instability of their fracture-dislocations after being allowed out of bed. Of these, two had cervical injuries, in one the spine eventually becoming stable after six months in a collar, the other having a fusion performed in another hospital. The other two patients had dorso-lumbar fracturedislocations and one became stable after an additional eight weeks in bed, the other finally uniting in a position of increased deformity after six months in a plastic corset.

\section{DISCUSSION}

The authors have tried to analyse the effect of a method of initial treatment, namely of postural reduction, on a material which is homogeneous. All cases are 
due to closed trauma of the spine. With few exceptions (which are excluded), the whole of the initial treatment was carried out by them. So also were the numerous neurological examinations from the start to the end of rehabilitation and discharge. They are fully conscious of the shortcomings which are inevitable in any attempt to compress the many variations of detail into categories which make grouping and analysis possible. Previous authors have described the incidence of neurological change in traumatic paraplegia and tetraplegia. Guttmann (I963) divided his patients' neurological lesions into complete and incomplete, improved, unchanged and deteriorated (these same patients are included in the present more detailed study). Hardy (I965) described patients with dorso-lumbar lesions in some detail but did not define different degrees of improvement. Geisler et al. (I966) included open spinal injuries and also did not attempt to define the degree of improvement.

We have not quoted any percentages in our results. Even with the large numbers involved we think it more appropriate to display the results in a form which other workers can use for direct comparison. The most interesting findings are:

I. The difference in the causes of the accident in the four main groups.

2. The large numbers of fractures and fracture-dislocations which were partially or completely reduced.

3. The low incidence of late vertebral instability, thus demonstrating that as long as the patients have an adequate time in bed there is no justification for early platings or fusions in order to prevent late instability. The time our patients were kept in bed before sitting up (see Results) is somewhat long, but we think that the results justify this. The time spent in bed is not wasted as physiotherapy and occupational therapy prepare the patients both physically and mentally for the next stage of their rehabilitation.

4. We have analysed the neurological results in as much detail as possible in relation to the bony lesions and the degree of reduction. Throughout the tables a small number of initially complete neurological lesions become incomplete and a larger number of incomplete lesions improve. There is, however, no clear correlation between the types and degree of the vertebral injury and the severity of the neurological lesion, nor is there any correlation between the degree of reduction achieved and neurological recovery. Whereas we consider it desirable to reduce the fractures and dislocations and essential to achieve vertebral stability, failure to reduce does not exclude the possibility of excellent neurological recovery in some cases.

We have only presented the neurological results in terms of our arbitrarily defined five degrees of neurological involvement $(A, B, C, D, E)$. We also attempted to analyse the incidence of small changes in the upper neurological level (lesions rising by more than four segments have been previously described, Frankel, 1969). We found that the recording of the neurological lesion on admission and discharge as done in this survey does not do justice to this very interesting topic and we intend to give these results in detail in a subsequent paper, together with an analysis of the associated injuries and the incidence of multiple fractures and pre-existing bony abnormalities, congenital or acquired.

The controversy between those advocating operative initial treatment and those who, like ourselves, feel that postural reduction (with occasional exceptions) offers the best chance for both skeletal stability and neurological recovery will go 
on. We hope that those who do not share our view will take the opportunity of comparing their results with ours.

We believe that the day may not be far off when Sir Ludwig Guttmann's fundamental contribution, the advocacy of postural reduction as the method of choice for the initial management of closed injuries of the spine with paraplegia and tetraplegia, will receive the general recognition it deserves.

\section{To be concluded}

\section{SUMMARY}

Six hundred and twelve patients with closed spinal injuries are described. The incidence of various types of fracture and fracture-dislocation and the degree of reduction achieved by postural reduction is analysed in relation to the initial and late neurological lesions. The average time that the patients were kept in bed is given for the various types of skeletal injury. Only 4 patients developed late instability of the spine.

\section{REFERENCES}

Cloward, R. B. (I96I). F. Neurosurg. 18, 201.

Covalt, D. A., Cooper, I. S., Hoen, T. I. \& Rusk, H. A. (1953). F. Am. med. Ass. 89, I5 I. Frankel, H. L. (1969). Int. F. Paraplegia, 7, I I I.

Geisler, W. O., WynNe-Jones, M. \& Jousse, A. T. (I966). Med. Servs F. Can. 22, 5I2. Guttmann, L. (1953). In Medical History of the Second World War, Surgery, ed. Cope, Z., p. 422. London: H.M. Stationery Office.

Guttmann, L. (1963). Proceedings of a Symposium on Spinal Injuries, ed. Harris, P., pp. 80-92. Royal College of Surgeons of Edinburgh.

Hardy, A. G. (1965). Int. F. Paraplegia, 3, I I2.

HARris, P. (1963). Proceedings of a Symposium on Spinal Injuries, pp. IOI-II2. Royal College of Surgeons of Edinburgh.

Holdsworth, F. W. (1963). F. Bone ft Surg. 45-B, 6.

Holdsworth, F. W. \& Hardy, A. G. (1953). F. Bone ft Surg. 35-B, 540. 